\title{
Propina y ECONOMía DEL DON: \\ la subcontratación de empacadores en supermercados de Bogotá
}

\author{
DAVID DíEZ \\ Profesor de la Universidad Nacional de Colombia, programa \\ DE BECAS PARA ESTUdiantes SOBRESALIENTES DE POSGRAdo \\ dadiezg@gmail.com
}

\section{Resumen}

[ STE ARTÍCULO, FRUTO DE UN ESTUDIO ETNOGRÁFICO SOBRE LA PROPINA EN SUPERMERCADOS [ de Bogotá, muestra cómo los intercambios de bienes y servicios entre clientes y empacadores, en medio de los que circula la propina, están atravesados por la economía del don y la del capitalismo. Por medio del análisis de interacciones cotidianas y de mi experiencia subjetiva como empacador destaca la capacidad de adaptación de los empacadores a su entorno laboral. Muestra cómo su salario deja de ser asumido por los supermercados y pasa a depender de las cooperativas mediante las cuales los empacadores son subcontratados. Este cambio es el resultado de la desregulación laboral del capitalismo flexible, que se refleja en la proliferación de cooperativas de subcontratación de empacadores, constituidas en Colombia desde 1996.

PALABRAS ClAVE: propina, economía del don, subcontratación, jóvenes empacadores, supermercados.

\begin{abstract}
THIS ARTICLE PRESENTS THE RESULTS OF AN ETHNOGRAPHIC STUDY ON TIPPING PRACTICES IN Bogotá supermarkets. I show how the goods and services exchanges between customers and packagers, among which the tip circulates, are permeated by gift and capitalist economies, two forms of exchange that despite their conceptual differences become entwined to strengthen the process of labor deregulation. Moreover, I examine the ways in which customers and packagers use this combination by analyzing daily interactions, my experience as a packager, and stressing the packagers ability to adapt to their labor environment. Supermarkets no longer pay for packagers' wages since they outsource their packaging needs to independent cooperatives, who in turn subcontract packagers. Finally, I argue that the proliferation of packager cooperatives in Colombia since 1996 reflects the labor deregulation supported by flexible capitalism.
\end{abstract}

KEY WORDS: Tipping, gift economies, outsourcing, packagers, supermarkets.

$$
\frac{\text { Revista Colom biana de Antropología }}{\text { Volumen 42, enero-diciembre 2006, pp. 249-276 }}
$$




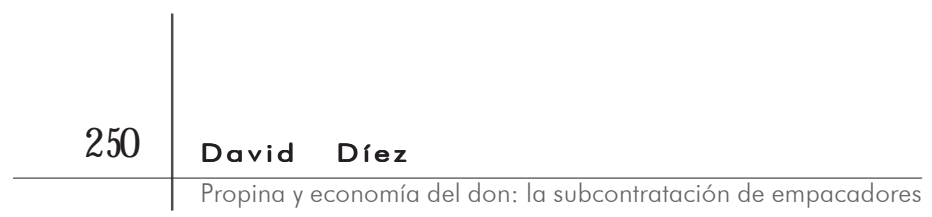

\section{INTRODUCCIÓN *}

L DESARROLLO DE LA DISCIPLINA ANTROPOLÓGICA HA PERMITIDO RECO-

- nocer que las relaciones establecidas entre los seres humanos

L en sus distintas dimensiones -económica, política, religiosa y ecológica, entre otras- varían de acuerdo con las condiciones sociales y culturales propias de diversos contextos geográficos e históricos; es decir, que tales relaciones no son condiciones naturales o innatas en la humanidad, sino resultado de la articulación y disyunción de procesos de interacción sociocultural.

En la actualidad sigue siendo pertinente acentuar tal reconocimiento, sobre todo en relación con la dimensión económica de la vida social. Dada la predominancia y autonomía que el sistema económico capitalista ostenta en la mayoría de sociedades del mundo, es común que sea visto como una condición natural de todo intercambio económico y no como una construcción social y cultural que corresponde a un momento histórico particular, que coexiste y se yuxtapone a otros códigos económicos.

Al tiempo que los criterios del mercado capitalista permean cada vez más la mayoría de las dimensiones de la vida humana, en distintos escenarios de la vida social se manifiestan intercambios que, a pesar de estar inmersos en ese mercado, se desarrollan según regulaciones no propiamente capitalistas, como las que corresponden a la economía del don. No obstante, por lo menos en el caso que analizaré, el sistema imperante se apropia de estas regulaciones, de manera que terminan dinamizándolo.

Los anteriores argumentos se materializan en el escenario de algunos supermercados de Bogotá en los que asumí dos roles

* Este artículo presenta los principales resultados de mi trabajo de grado para optar al título de antropólogo de la Universidad Nacional de Colombia (Díez, 2005, dirigido por el profesor Carlos Miñana y coevaluado por la profesora Martha Zambrano, a quienes agradezco por su apoyo y valiosos aportes.

1 Me gustaría utilizar un lenguaje no sexista para escribir este texto, sin tomar el masculino gramatical como "genérico", pero el español es un idioma poco propicio para este ejercicio. Por tanto, y para facilitar la lectura, en algunas ocasiones recordaré que los "genéricos" tienen sexo. Por otro lado, quiero aclarar que durante la investigación que sustenta este artículo mi mirada estuvo dominada por una "ceguera de género", que me llevó a paralelos entre 2001y 2003 mientras hacía "trabajo de campo" como estudiante de antropología, era un actor "natural" del escenario, debido a mi vinculación a la cooperativa de trabajo asociado que administra el personal de empacadores ${ }^{1}$ de dichos supermercados. En estos establecimientos, la propina que los clientes 


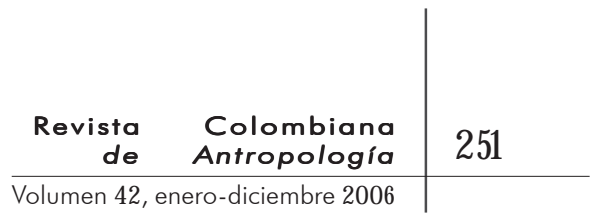

suelen dar, o no dar, a los empacadores se asocia a la economía del don, al cooperativismo y al capitalismo, constituyendo una amalgama $^{2}$ que potencia varias de las tendencias estructurales del sistema capitalista. Al hablar de este sistema me acojo a la visión marxista del mismo ${ }^{3}$. Para Marx (1946), la principal característica del capitalismo radica en que la clase trabajadora, despojada de la propiedad o el control de los medios de producción, debe vender su fuerza de trabajo a cambio de un salario. Mediante este proceso, el comprador de tal fuerza, quien suele ostentar los medios de producción, obtiene una ganancia o plusvalía al apropiarse de una cantidad del costo del tiempo empleado por el trabajador para producir una mercancía u ofrecer un servicio. En resumen, el capitalismo depende de la fuerza de trabajo "libre" asalariada.

A lo anterior debe sumarse el papel del estado como mediador de las relaciones obrero-patronales, lo que implica la expedición de leyes y el establecimiento de mecanismos de control que regulen los contratos de venta y compra de la fuerza de trabajo, particularmente en relación con el costo social de la misma, calculado según la cantidad de tiempo y la complejidad del conocimiento o la técnica necesaria para desarrollar los distintos tipos de trabajo, material e inmaterial, entre otros factores. Esta mediación estatal lleva a que quienes intercambian bienes o servicios según criterios capitalistas -sobre todo en el marco del sector formal-, establezcan de antemano el precio de los mismos, orientados por parámetros impersonales. En tales intercambios es indispensable el uso de una moneda estándar que permita establecer la equivalencia entre lo que se da $y$ lo que se recibe a cambio.

Por otra parte, al hablar de la economía del don me refiero a lo que Bourdieu (1997) ha denominado la eco-

- pasar por alto las posibles diferencias y desigualdades entre hombres y mujeres en el ámbito estudiado. Sin embargo, al final del artículo señalo de manera breve nuevos intereses de investigación que he comenzado a desarrollar con el fin de complementar el presente estudio desde una perspectiva de género, en el marco de la maestría en estudios de género, mujer y desarrollo que actualmente curso en la Universidad Nacional de Colombia (véase Díez, 2006).

2. La palabra "amalgama" alude a la unión o mezcla de dos cosas de naturaleza distinta. Tal noción representa una metáfora del punto central de este artículo, a saber, la mezcla entre dos formas de intercambio que tradicionalmente han sido consideradas propiedades exclusivas de distintos tipos de sociedades: por un lado, la economía del don y, por otro, la economía capitalista; ambas articuladas con el cooperativismo, sobre el que hablaré en la segunda parte de este texto.

3 Siguiendo a Roseberry (1997), considero válido retomar a Marx con el fin de destacar su importancia para la antropología, acudiendo directamente a textos como El Capital, incluso sin entrar en detalle sobre los múltiples desarrollos que se han propuesto a partir de esta obra desde distintas áreas de conocimiento. 


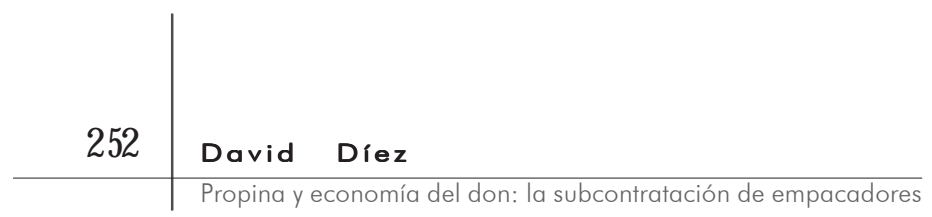

nomía de los bienes simbólicos, a partir del desarrollo del concepto de don propuesto por Marcel Mauss (1971) a propósito de sus estudios con grupos humanos "primitivos", en sus términos, como los tinklit y los haida del noroeste americano de principios del siglo veinte. Esta economía corresponde a transacciones en las que no existe contrato formal de intercambio en el que se determinen, de manera estándar, los precios de las mercancías o servicios transados. En este caso, las reglas de juego están dadas en la interacción misma entre los actores, de modo que en vez de las normas estatales e impersonales existen otros reguladores de los precios de los bienes -materiales o inmateriales- que se intercambian, que son de carácter personal: palabras, miradas, gestos, movimientos corporales, entre otros elementos constitutivos de la comunicación verbal y no verbal. Así mismo, en esta economía suele haber asimetría entre lo que se da y lo que se recibe, sin que se pueda acceder a medios legales para exigir la retribución respectiva, como sucede en el caso de los intercambios capitalistas ${ }^{4}$. Así mismo, y en contraste con los intercambios propios del capitalismo, en el caso del

4. La posibilidad de recurrir a medios legales ante el incumplimiento de las normas de los intercambios capitalistas es válida ante todo para quienes se inscriben en el sector formal, pues en el caso de los trabajadores informales de Colombia es más difícil que puedan hacer valer sus derechos como vendedores o prestadores de servicios, recurriendo a tales medios. don es frecuente la ausencia de una moneda estándar que establezca equivalencias entre distintos bienes y servicios, pues estos últimos pueden transarse unos por otros sin la intermediación de un pago monetario, lo que aumenta las posibilidades de que las transacciones sean asimétricas.

Para mostrar cómo se yuxtaponen la economía del don y la economía del capitalismo en el escenario de los supermercados estudiados, organizaré este texto de la siguiente manera: primero, describiré el tipo de contratación de los empacadores; en seguida trataré la relación entre la economía del don y la propina; luego analizaré algunos usos que clientes y empacadores hacen de las formas de intercambio que subyacen a la propina, incluyendo referencias a mi experiencia subjetiva como empacador; por último señalaré cómo el don, el cooperativismo y el capitalismo flexible contemporáneo se articulan para potenciar un proceso de desregulación laboral en supermercados de Bogotá en particular y de Colombia en general. 


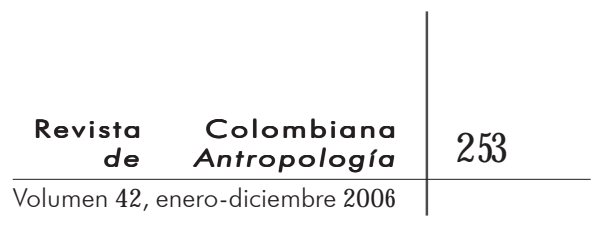

\section{LA PROPINA COMO SALARIO \\ DE LOS EMPACADORES}

OS EMPACADORES QUE LABORAN EN LOS SUPERMERCADOS OBJETO DE este estudio, con edades entre dieciocho y veinticuatro años, se encuentran vinculados bajo la calidad de asociados a una cooperativa de trabajo a la que asignaré el seudónimo "Verde". Desde 1999, esta entidad ha administrado el personal a cargo del servicio de empaque de los productos registrados y pagados en las cajas de los supermercados de una de las principales cadenas comerciales del país, a la que daré el seudónimo "Azul".

La remuneración por el trabajo de los empacadores consiste en una compensación fija y una compensación variable. La primera corresponde al pago de su seguridad social ${ }^{5}$. Para cubrir ese costo, Verde cuenta con el dinero que Azul le transfiere por hora/empacador, bajo el marco de una orden de prestación de servicios. Durante los últimos años, la tarifa por hora/empacador ha oscilado entre 1500 y 1700 pesos $^{6}$ (Verde, 2002). La Compensación variable consiste en las propinas que los clientes brindan de manera voluntaria a los empacadores en retribución por su servicio y atención en las cajas de pago. En la mayoría de los casos, estas propinas corresponden a cantidades que oscilan, según el sector, el tipo de clientes asiduos al supermercado, además de otros factores, entre $\$ 50$ y $\$ 5000$, según lo constaté en campo, aun cuando en ocasiones los clientes dan a los empacadores, bajo el carácter de propina, bienes de consumo u objetos como llaveros o similares.

5 En el rubro de seguridad social se encuentra la afiliación a una entidad promotora de salud (EPS), a una administradora de riesgos profesionales (ARP), a una administradora de fondos de pensiones (AFP) y a una caja de compensación familiar.

El tipo de relación establecida entre Azul y Verde es un ejemplo paradigmáti-

6. En julio de 2006, un dólar equivalía a cerca de 2.400 pesos colombianos.

co en el caso colombiano. Entre las cadenas de supermercados que manejan ese modelo de contratación se encuentran Éxito, Ley, Pomona, Cafam y Colsubsidio. Existen otras cadenas como Olímpica, cuyo servicio de empaque es asumido por "trabajadores voluntarios" entre dieciséis y veinticinco años, quienes deben cubrir el costo de su seguridad social de manera independiente, como requisito para trabajar en los supermercados y de ese modo recibir propinas, que constituyen el único tipo de compensación 


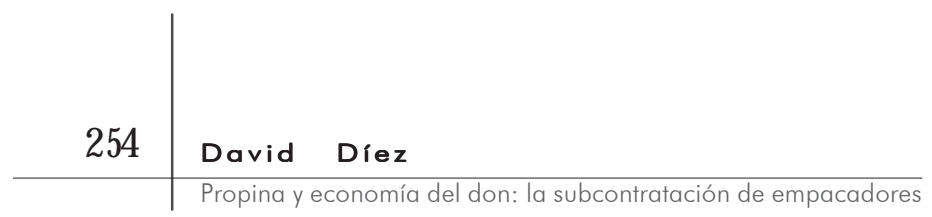

por su trabajo. Estos empacadores no pertenecen a ningún tipo de entidad. Existe un tercer modelo menos frecuente, como el que maneja Carrefour, en el que los empacadores son empleados directos del supermercado, reciben un salario mínimo con todas las prestaciones legales y tienen prohibido recibir propina.

En el caso que nos ocupa, los empacadores están insertos en un mercado laboral que les ofrece seguridad social a cambio de su fuerza de trabajo, pero les niega la posibilidad de obtener un ingreso económico fijo o salario básico, al dejar en manos de los clientes la potestad de decidir cuánto merecen recibir como compensación por su trabajo. Al igual que los demás individuos inmersos en el sistema capitalista actual, los empacadores necesitan dinero que les permita acceder no sólo al sistema de salud, sino también a educación, alimentación, vivienda y recreación, entre otros. Ese dinero sólo lo pueden obtener por medio de las propinas de los clientes, quienes están en libertad de brindarlas. Tal libertad se debe, entre otros factores, a que en Colombia no existe legislación que obligue a los clientes a dar propina a los empacadores en retribución por su servicio. Por otro lado, aunque el Código sustantivo del trabajo señala que "las propinas no constituyen salario", y que "no puede pactarse como retribución del servicio prestado por el trabajador lo que éste reciba por propinas” (República de Colombia, 2003 49), desde la promulgación de la ley 79 de 1988, hasta hoy, el estado colombiano ha otorgado a las cooperativas del país un notable grado de autonomía para determinar, por medio de sus estatutos internos, las formas de compensación que consideren acordes con su objeto social y el bienestar de sus asociados.

Aun cuando desde 1996, año en el que se creó la primera cooperativa de empacadores de supermercados y apareció el concepto de compensación variable, la propina ha pasado a constituir buena parte del "salario" de los empacadores, no por ello ha dejado de ser un rubro vinculado a criterios de intercambio afines a la economía del don. Estos criterios difieren de la noción capitalista de salario por las siguientes razones: I) el valor de la propina no se determina por medio de un contrato formal de acuerdo con parámetros impersonales de tipo legal, sino que depende de la voluntad del cliente, quien puede asignarlo según su criterio; 2) para influir sobre la voluntad del cliente, el empacador no puede apelar a recursos impersonales, sino que debe aprovechar la comunicación verbal y no verbal para sacar 


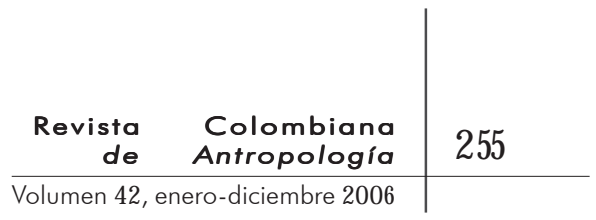

el mejor provecho de la interacción entre ambos en el contexto de las cajas de pago; 3 ) existe una asimetría latente entre cliente y empacador, pues mientras el empacador está obligado a ofrecer un servicio al cliente ${ }^{7}$, este puede negarse a retribuir ese servicio o retribuirlo con una cantidad monetaria o bien de consumo que no corresponda con las expectativas del empacador, pero que debido a la falta de parámetros imper-

7. Más adelante señalaré cómo los empacadores desarrollan tácticas para evitar prestar su servicio a determinado tipo de clientes, con el fin de maximizar las posibilidades de recibir propina.

sonales y reglamentaciones

legales debe ser aceptado por el mismo. Así pues, la propina está regulada por parámetros afines a la economía del don, más que por criterios capitalistas. De hecho, en términos legales, el Ministerio de Trabajo y Seguridad Social, actual Ministerio de la Protección Social, plantea que la propina es "un regalo, una especie de retribución que los usuarios o clientes otorgan a los empleados de los establecimientos por efecto, o por el hecho, de la prestación de un servicio" (Ministerio de Trabajo, citado en Ruiz y Mesa, 1985 D.

\section{LA PROPINA Y LA ECONOMÍA DEL DON EN LOS SUPERMERCADOS}
A ECONOMÍA DEL DON O DE LOS BIENES SIMBÓLICOS SE INSCRIBE en escenarios caracterizados por la "creación de las condiciones objetivas para que los agentes sociales tengan interés en el desinterés" (Bourdieu, 1997: 160). En estos escenarios, la inclina- ción a aparentar desinterés ante la posible obtención de benefi- cio mediante un intercambio, resulta ser un acto económico racional. El "interés en el desinterés” está ligado al ocultamiento de una verdad estructural latente: el hecho de que todo regalo constituye "una agresión a la libertad de quien recibe. Contiene una amenaza: [...] es una forma de atar, haciendo que la gente se sienta obligada" (Bourdieu, 1997: 162). No obstante, Bourdieu sugiere que esa verdad estructural se reprime o disimula colec- tivamente, tanto por quienes dan como por quienes reciben. Se tiende a negar la verdad del intercambio, del interés económico subyacente, que "representa la aniquilación del intercambio de obsequios" (1997: 162). 


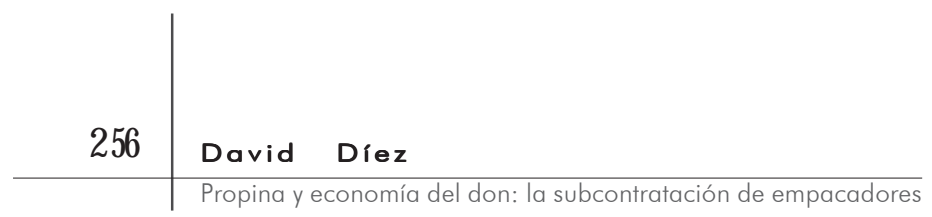

En el caso que nos atañe, el empacador ofrece al cliente un servicio que consiste en empacar sus productos, en atenderlo con amabilidad y, cuando el cliente lo acepta, ayudarle a llevar sus paquetes a su destino particular: domicilio, transporte público o particular, entre otros. Así mismo, la relación clienteempacador se inscribe en un intervalo de tiempo que transcurre entre el momento en el que el empacador presta el servicio y el instante en que el cliente retribuye o no ese servicio con una propina. Todo este intervalo, pero sobre todo su final, se encuentra atravesado por un halo de incertidumbre: el fruto del intercambio puede concluir o no con una propina. El inicio del intervalo se da cuando el cliente llega a una caja de registro para cancelar sus compras y se encuentra cara a cara con un empacador. Debido a que este se presenta allí bajo el rol de empleado, mientras que el cliente asume el papel de comprador, el primero está, en cierto grado, subordinado al segundo: se encuentra restringido por reglas y procedimientos protocolares cuyo cumplimiento supervisan el coordinador de empacadores y el "jefe de cajas”, entre otros personajes. Así, en ese primer momento, el empacador debe propender, como mínimo, a ser amable con el cliente; empacar sus productos de manera rápida, eficiente y cuidadosa, clasificándolos

8. El "jefe de caja" está encargado de supervisar el trabajo de los cajeros, los auxiliares de mercadeo y los empleados subcontratados por el supermercado, entre ellos los empacadores. según su tipo, entre otros factores que constituyen su servicio. No en todas las oportunidades y no todos los empacadores ofrecen en el primer momento del intervalo el mismo servicio. Existen diversas variables que condicionan la calidad de este, entre las que se encuentran el estado de ánimo del empacador; la cantidad de propinas que haya acumulado durante la jornada; el flujo de clientes en el almacén; las impresiones que el cliente que llega a la caja de registro le produzca al empacador o el conocimiento previo que este tenga de aquel; entre otras.

De manera recurrente, cuando un cliente llega a la caja de registro, algunos empacadores, dependiendo no sólo de la cantidad y el tipo de artículos del mercado en cuestión, sino también de las posibilidades que perciban de que el cliente acepte que lo acompañen a llevar sus productos a su destino, acercan o no un carrito de mercado desocupado para ubicar en él los respectivos paquetes; al igual que se esmeran o no por ser espe- 


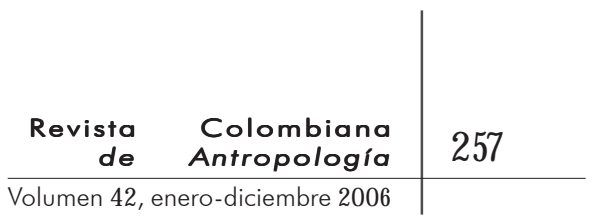

cialmente amables. Estos actos dan cuenta de una expectativa creada en la mente de los empacadores: acercan un carrito, ubican allí los paquetes y tratan con especial formalidad al cliente, para luego ofrecerse a llevar sus paquetes. ¿Qué pasa si el cliente acepta ese ofrecimiento? Si lo hace, se completa el primer momento del intervalo. Es decir, mediante tal aceptación el cliente recibe el servicio que ofrece el empacador, que se presenta en apariencia como un regalo, como un favor "desinteresado". Al dar ese servicio-regalo, los empacadores buscan que el cliente se sienta comprometido a retribuirlo con la entrega de una propina-regalo al final de su interacción. Como señalé, el obsequio implica, en cierto modo, una agresión a la libertad de quien lo recibe, es una manera de "atar" al receptor, de hacerlo sentir en la obligación moral de devolver. No obstante, la aceptación del servicio-regalo por parte del cliente no garantiza al empacador que posteriormente reciba una propina, pues a diferencia de los intercambios propiamente capitalistas, regidos por criterios impersonales, aquí todo depende de parámetros personales, razón por la cual existirá siempre la posibilidad de no recibir nada a cambio. Como señala Bourdieu, "siempre hay ingratos".

En estos casos, en contraste con las transacciones capitalistas, no existen sanciones sociales ni legales frente a la no devolución de lo recibido, pues los regalos pueden o no ser devueltos. Es quizá por esa falta de garantías que los empacadores tienden a categorizar a los clientes y evitan ofrecer su servicio-regalo a

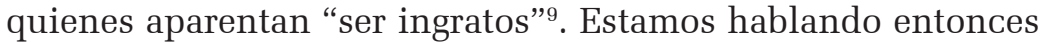
de un servicio-regalo en apariencia voluntario. Hemos visto que la economía de los bienes simbólicos

9. Tal categorización se da a partir del establecimiento de distintos estereotipos, algunos de los cuales examinaré más adelante. está atravesada por la negación del interés económico subyacente. Esa negación genera una situación paradójica en los supermercados: es claro que el empacador está interesado en recibir dinero por parte de los clientes, sobre todo porque su ingreso económico depende en buena medida de las propinas. Sin embargo, el acto de ayudar a los clientes a llevar sus paquetes, así como la amabilidad implícita en el mismo, en cuya retribución el empacador espera recibir una propina, debe presentarse como "voluntario" o “desinteresado". Ese carácter "voluntario" no sólo es algo en lo que se enfatiza en los cursos de inducción que 


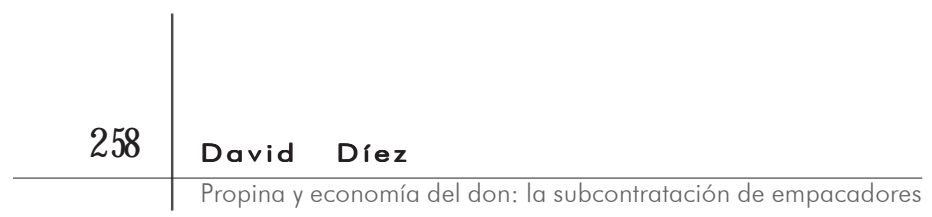

reciben los empacadores antes de iniciar su trabajo en los supermercados; es, sobre todo, un elemento constitutivo de un código cultural que condiciona los intercambios económicos entre clientes y empacadores en los supermercados: la economía del don.

\section{USOS DEL CÓDIGO CULTURAL DEL DON}

A NOCIÓN DE "USO" QUE UTILIZARÉ AQUí ES AFÍN A LA ESBOZADA POR Michel de Certeau (1996), quien propone una teoría de las prácticas para dar cuenta de las diversas formas como los individuos, durante su quehacer diario, usan diversos códigos culturales bajo la forma de tácticas. Estas se basan en un cálculo que se da en el "ambiente" mismo en el que actúan los individuos, que apunta a "coger 'al vuelo' las posibilidades de provecho” (1996: L). Teniendo en cuenta lo anterior, a continuación mostraré cómo, tanto empacadores como clientes, hacen uso del código del don que subyace a la propina, es decir, señalaré cómo ambos, mediante diversas tácticas, ponen en juego ese código. Debido a que sería imposible dar cuenta de todas las tácticas que a diario utilizan clientes y empacadores, a continuación analizaré sólo algunas de las interacciones observadas y vividas en el transcurso del trabajo de campo, que resultan pertinentes para los objetivos de este texto.

\section{Las caras de los clientes}

F N EL CONTEXTO DE SUS INTERACCIONES COTIDIANAS EN LAS CAJAS 4 de pago, los empacadores y los clientes se atribuyen cierto tipo de valoraciones. Siguiendo a Goffman, una interacción puede definirse como "la influencia recíproca de un individuo sobre las acciones del otro cuando se encuentran ambos en presencia física inmediata” (1959. 27). Tales valoraciones se basan en las impresiones (Goffman, 1959) que unos y otros reciben mediante las expresiones comunicativas que transmiten en su interacción. Las impresiones llevan, a su vez, a que ambos actores asuman distintos comportamientos. Para el caso que nos ocupa, tanto clientes como empacadores, incluso sin 


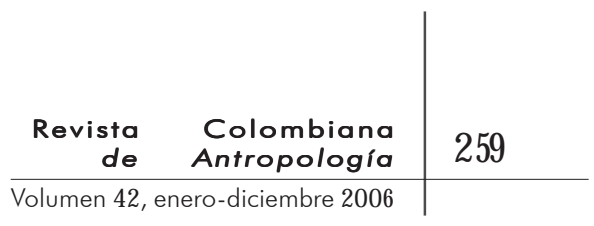

que tengan la intención consciente de seguir una línea ${ }^{10}$, la siguen. Al hacerlo, producen una impresión en su interlocutor, ostentan ante este una cara determinada, es decir, una serie de atributos sociales que el interlocutor puede asociar con determinadas acciones futuras.

10. Al hablar de línea Goffman se refiere a "un esquema de actos verbales y no verbales por medio de los cuales [un individuo] expresa su visión de la situación, y por medio de ella su evaluación de los participantes, en especial de sí mismo. No importa que la persona tenga o no la intención de seguir una línea; descubrirá que en la práctica así lo ha hecho" (1967: 13.

Siguiendo a Goffman, la capacidad de un individuo para producir impresiones involucra dos tipos de actividad significante: las expresiones que $d a$ y las que emanan de él. Las primeras incluyen los símbolos verbales que usa para transmitir la información que él y los otros atribuyen a esos símbolos. Las segundas se componen de una amplia gama de gestos, miradas, modos de mover el cuerpo, maneras de vestir, entre otros aspectos que constituyen la comunicación no verbal, es decir, la comunicación en el sentido general del término. Así pues, cuando un individuo se presenta ante otros, estos son impresionados por él mediante las expresiones que $d a$ y emana. Según Goffman, tales expresiones tienen un carácter promisorio. Los observadores actúan en función de ellas, pero sólo cuando la interacción con el individuo en cuestión finaliza pueden saber si el valor que han recibido a cambio de sus acciones corresponde o no con las impresiones recibidas a partir de las expresiones del individuo (Goffman, 1959. 14-15).

Si bien este fenómeno se da en toda clase de encuentros y espacios sociales, su manifestación es más notoria en establecimientos comerciales en los que clientes y prestadores de servicios se encuentran cara a cara (Goffman, 1959). En tales escenarios, cuando un individuo se presenta ante otros estos suelen tratar de obtener información acerca de él o de poner en juego la que ya tienen. Así, se interesan por su estatus socioeconómico general, la actitud que tiene hacia ellos, su concepto de sí mismo, entre otros aspectos. Ese interés, más que un fin en sí mismo, encierra una serie de razones prácticas: "La información acerca del individuo ayuda a definir la situación, permitiendo a los otros saber de antemano lo que él espera de ellos y lo que ellos pueden esperar de él. Así informados, los otros sabrán cómo actuar a fin de obtener de él una respuesta determinada" (Goffman, 1959. 13).

Teniendo en cuenta los planteamientos anteriores se puede establecer un vínculo entre la economía del don, los conceptos 


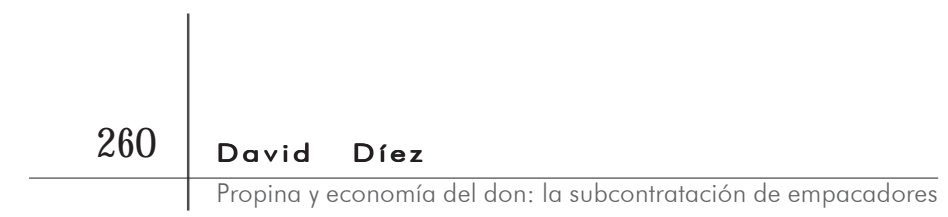

de línea, cara e impresión, y las tácticas de los clientes y los empacadores en los supermercados de Bogotá. La economía del don se escenifica en el transcurso de un intervalo de tiempo determinado. Desde el inicio de ese intervalo, es decir, desde el momento en el cual el cliente llega a la caja de registro, el empacador recibe de él una serie de impresiones basadas en las expresiones verbales y no verbales o en la línea que el cliente expresa. Esta línea hace que el cliente irradie una imagen constituida por una serie de atributos sociales, es decir, una cara. Dependiendo de la cara que el empacador perciba del cliente, asumirá cierto tipo de comportamiento. Del mismo modo, según la cara que el cliente ostente -de manera consciente o no-, actuará de manera que sus comportamientos mantengan cierto grado de correspondencia con esa cara en particular. Sin embargo, sólo al final del encuentro el empacador sabrá si su lectura ha sido apropiada y si sus acciones han correspondido o no con la cara del cliente. Los modos de acción mediante los cuales el cliente pretende manejar la situación para que el empacador perciba que él posee una cara en particular, así como las formas en que el empacador actúa de acuerdo con la línea que siga el cliente, pueden ser vistos como tácticas. Todos estos elementos configuran un lenguaje regulador de la economía del don, de carácter contextual

11 La mayor parte de estas referencias se basan en y personalizado, en contrasnotas de mi diario de campo. te con las regulaciones impersonales propias de los intercambios capitalistas. Veamos lo anterior mediante referencias de campo concretas ${ }^{11}$.

\section{LA RISA DE LOS EMPACADORES/ LAS "CACHETADAS" DE LOS CLIENTES}

N 2001, DURANTE MI PRIMERA JORNADA LABORAL COMO EMPACADOR, - me disgusté debido a que una clienta, luego de acompañarla a - llevar los paquetes a su domicilio, no me ofreció una propina monetaria, sino una gaseosa. Esperaba recibir dinero y no un bien de consumo. Sin embargo, cuando ella me preguntó si debía pagarme algo, automáticamente respondí: "No señora, es voluntario”. En mi modo de actuar, así como en mi sentimiento de rabia y frustración, se puede leer una de las verdades dobles de los 


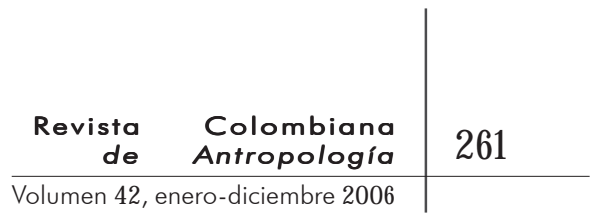

intercambios de bienes simbólicos propios de la economía del don: aun cuando esperaba recibir dinero, no debía hacerlo explícito; era necesario actuar como si en realidad no quisiera recibir$l^{12}$. Por otro lado, la entrega de una gaseosa bajo el carácter de propina reafirma el intercambio que establecen clientes y empacadores, como una transacción mediada por el don. Rememora también el tradicional trueque, pues en este caso no existe una moneda estándar que cumpla el papel de intermediaria, sino que el servicio del empacador se transa directamente por un bien de consumo. Esto habla además de las contradicciones a las que se deben enfrentar los empacadores al ver retribuido su trabajo por elementos distintos al dinero, que constituyen, más que el pago por su servicio, un regalo, una cortesía que los clientes pueden o no ofrecer en contraprestación por ese servicio.

Al observar lo sucedido, algunos empacadores esbozaron sonrisas burlonas en su rostro. ¿A qué se debían? Luego de trabajar unos meses en varios supermercados noté que en repetidas ocasiones, cuando los empacadores "antiguos" observaban a un "novato" ofrecer su servicio de acompañamiento a un cliente conocido por su tendencia a evitar ese ofrecimiento o, en términos de los empacadores, a "cachetear", se burlaban de él. Los empacadores usan la palabra "cachetada" para referirse al acto mediante el cual un cliente, o bien no acepta el ofrecimiento de ayuda para llevar sus paquetes por fuera del supermercado -cachetada tipo A-, o bien, aun cuando lo acepta, una vez el empacador ha llevado los paquetes a su destino no retribuye ese servicio con una propina monetaria -cachetada tipo B-. Además de los dos tipos anteriores existe una tercera categoría: en esta, el empacador es coautor de la cachetada que él mismo recibe-cachetada tipo $\mathrm{C}-{ }^{13}$, lo que explicaré más adelante.

Como lo destaca Goffman, cuando los prestadores de servicios se encuentran con un cliente a quien no conocen con anterioridad, pueden "recoger indicios de su conducta y aspecto que les permitirán aplicar su ex-

12. El uso de mi experiencia subjetiva como herramienta para producir conocimiento social difiere de los lineamientos que suelen regir a las etnografías escritas en estilo clásico. En estas, la objetividad del "trabajo de campo" radica en la "neutralidad" del etnógrafo en relación con sus sujetos de estudio. Rosaldo propone, en cambio, centrar la atención menos en la inalcanzable "neutralidad" y más en la posición de sujeto del investigador. Esto con el fin de sacar conclusiones fruto del análisis de la relación etnógrafo-sujetos de estudio, así como de construir relatos etnográficos realistas, en vez de creer ingenuamente en la ilusión positivista (Rosaldo, 1989.

13 Los empacadores como tal no suelen establecer diferencias entre estos tres tipos de "cachetadas". Sin embargo, he determinado tal clasificación para facilitar el análisis de los datos de campo. 


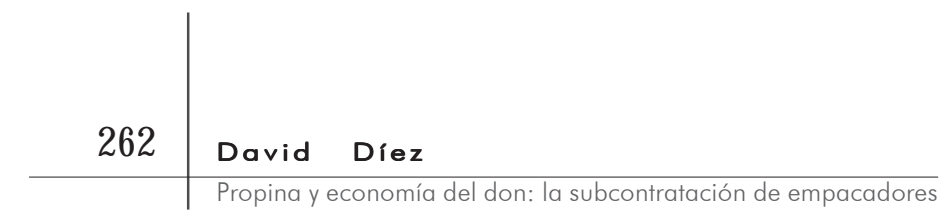

periencia previa con individuos aproximadamente similares al que tienen delante o, lo que es más importante, aplicarle estereotipos que aún no han sido probados" (Goffman, 1959. 13). Por otro lado, en las situaciones en las que se enfrentan con individuos conocidos gracias a experiencias previas a la interacción, "pueden confiar en suposiciones sobre la persistencia y generalidad de rasgos psicológicos como medio para predecir su conducta presente y futura" (Goffman, 1959. 13).

En el caso que narré a propósito de la primera cachetada que recibí siendo empacador, se trataba de una clienta asidua al supermercado, conocida por su costumbre de no dar propina monetaria a los empacadores, sino una bebida o, incluso, sólo un "gracias" como retribución por el servicio de empacar su mercado y llevarlo hasta su casa. En otras palabras, la clienta solía seguir una línea que había institucionalizado su cara en tanto cliente que no daba propina monetaria, aun cuando se le acompañara, es decir, que protagonizaba cachetadas tipo B.

Cuando un novato empaca el mercado de un cliente que los empacadores antiguos conocen por su tendencia a "cachetear", es decir, a no dar propina; o que, según su experiencia, ostenta una cara que da la impresión de que no la dará, y luego le ayuda a llevar ese mercado a su destino, está dando un regalo realmente voluntario, que no implica una retribución; es decir, está trabajando gratis. Tal hecho suele generar burlas entre los empacadores antiguos. Quizá todo se trate de una especie de rito de paso. Como me comentó el coordinador de empacadores del supermercado en el que inicié mi experiencia como empacador, "sólo con el tiempo entenderá qué es una 'cachetada". Como sucede en muchos otros espacios sociales -como las universidades, por ejemplo- los antiguos suelen divertirse mientras observan a los novatos cometiendo los errores que sólo aprenderán a evitar con el tiempo y la práctica.

Sin embargo, lo anterior no quiere decir que los antiguos tengan garantizado recibir siempre propina gracias a su conocimiento de las caras de los clientes. Se debe recordar que, tal como señala Bourdieu (1997), en los intercambios de bienes simbólicos propios de la economía del don reina la incertidumbre en vez de la certeza. Así, puede suceder que los antiguos se lleven una sorpresa. En una ocasión, por ejemplo, un novato, a quien llamaré "Edwin", atendió a un mensajero de un restaurante especializado en la preparación de tamales, quien solía ir diariamente 


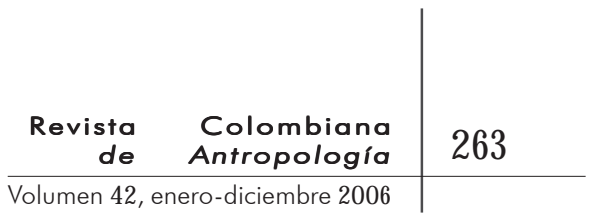

al almacén a comprar veinte o más kilos de garbanzo. Edwin fue bastante carismático con este cliente; conversaron mientras se registraban los productos y al final le dijo que si necesitaba ayuda. El mensajero le respondió que no era necesario pues tenía su moto muy cerca. No obstante, Edwin insistió en ofrecer su ayuda, de modo que el cliente terminó por aceptarla. Mientras tanto, dos empacadores, un cajero y yo, sonreíamos al ver la escena. Conocíamos muy bien al cliente y habíamos visto que siempre se negaba a aceptar que se le ayudara con sus paquetes; es decir, que siempre protagonizaba cachetadas tipo A. Luego de unos momentos, Edwin regresó al supermercado y nos preguntó por qué sonreíamos. Le dijimos que estaba perdiendo su tiempo, a lo cual respondió mostrando una moneda de $\$ 500$ que el mensajero le había dado como propina. Todos quedamos sorprendidos. Luego Edwin nos contó que aun cuando era novato en Verde, había trabajado varios meses para otra cooperativa en la cual la competencia entre empacadores es demasiado fuerte, por lo que es necesario, como dicen muchos empacadores, ser un "chulo", es decir, ser muy astuto y esforzarse al máximo para que todo cliente, sin importar su apariencia, es decir, su línea y su cara respectiva, dé siempre propina.

La manera de actuar de Edwin constituye más bien una excepción. Lo que constaté en campo es que muchos empacadores tienden más a evitar ofrecer su servicio a clientes conocidos por no dar propina o cuyas líneas les generan la impresión de que posiblemente no la darán, que a insistirles en acompañarlos y así recibir una propina. Tal evitación suele darse bajo la forma de cachetada tipo C, en la que los empacadores son coautores de la cachetada que reciben. En este caso, no ofrecen su servicio de acompañamiento al cliente en cuestión. Con el fin de desarrollar esta evitación, usan tácticas como, por ejemplo, no acercar un carrito de mercado vacío para ubicar en él los paquetes de los clientes, sino empacar los productos en el menor número de bolsas posible de modo que su ayuda para llevarlas se presente como innecesaria. Tal acto parecería sin sentido, pues ¿cómo entender que un empacador no ofrezca su ayuda para llevar los paquetes de un cliente, si la aceptación de esta sería, como ya he dicho, la manera de "comprometerlo" para que diera propina? Lo anterior se explica, en parte, si se tiene en cuenta que en varios de los supermercados estudiados los empacadores "salen por turnos". Es decir que según el orden de llegada al 


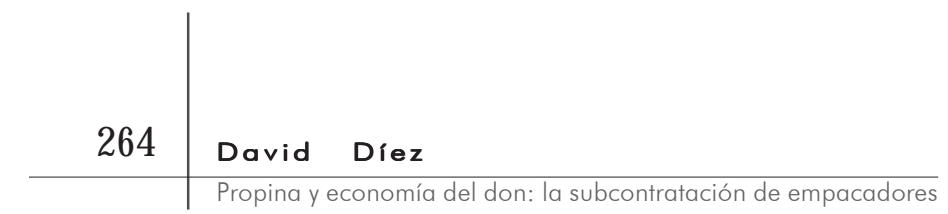

almacén durante el inicio de sus jornadas de trabajo establecen una secuencia según la cual a cada uno le corresponde un turno para "salir", es decir, para acompañar a un cliente con un carrito por fuera del supermercado. Normalmente se espera que al salir se reciba propina. Sin embargo, hay ocasiones en las que aun cuando se sale el cliente no da propina al empacador (cachetada tipo B). A partir de la acumulación de experiencia, los empacadores establecen entonces un estereotipo de los clientes que dan este tipo de cachetada, con quienes evitan salir para no perder su turno. Esta tendencia la he denominado "evadir la evasión", pues busca evitar ofrecer el servicio a clientes que evaden la lógica propia del regalo al no entregar una propina.

En cuanto a la cachetada tipo A, se da en las ocasiones en las que los clientes no aceptan que el empacador salga con ellos. La diferencia es que tal negación se da en el supermercado, de manera que el empacador no pierde su turno de salida. Los clientes acuden a distintas tácticas para evadir el servicio-regalo del empacador. Entre estas se encuentra, por ejemplo, la tendencia a decir, luego de que él ofrece su servicio, frases como "No gracias, es que tengo el carro cerca", o "No, es que tengo que esperar a que me recojan”, o "Son pocas bolsas, nosotros las llevamos". De la mano de estas frases van actos no verbales: los clientes se acercan al carrito en el que el empacador ubica los paquetes y comienzan a sacar las bolsas -como diciendo "No vamos a necesitar el carrito"-. Es usual también, sobre todo en los supermercados de sectores populares, encontrarse con clientes que traen costales, bolsas de basura o grandes maletas a las que trasladan los paquetes que el empacador ha depositado en el carrito. En síntesis, es reiterativa una lucha simbólica por el control de los carritos de mercado; control que, a su vez, determina la potestad sobre los paquetes. Los sucesos en los que se evidencia esta lucha resultan divertidos e interesantes para el observador atento.

Tanto el fenómeno de los "chulos" ejemplificado por Edwin, como el de los "evasores de evasiones", representado por muchos empacadores, y el de las "cachetadas tipo A" en el supermercado, dan cuenta de las tácticas. Cada variante muestra diversas formas mediante las cuales se pone en juego el código del don en el escenario estudiado.

Desde el punto de vista de los empacadores, es interesante observar cómo mediante sus tácticas sobrellevan un trabajo cuya compensación está muy mediada por la incertidumbre. Como lo 


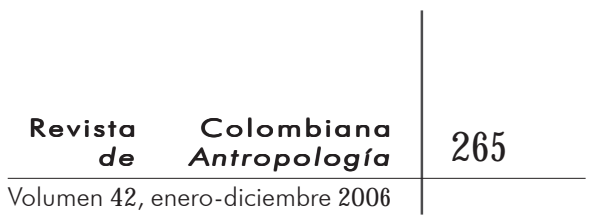

señala el antropólogo Alejandro Camargo (2005) para el caso de un escenario en apariencia ajeno al tratado aquí, como es el de la pesca en el río San Jorge (Córdoba y Sucre, Colombia), los seres humanos se adaptan y transforman el medio en el que habitan, entre otras razones, para disminuir o sopesar las variables que generan incertidumbre en sus formas de supervivencia. En esa adaptación la experiencia desempeña un papel fundamental. Por eso es que los empacadores aprenden, sólo a través del tiempo y de la práctica, a entender qué es una "cachetada" y a generar formas para evadirla. Sin embargo, siguiendo a Camargo, junto a la experiencia yace siempre el papel de "la suerte", de variables externas impredecibles y de condiciones socioeconómicas estructurales, muchas veces caracterizadas por la desigualdad. Así, sin importar la práctica acumulada por los empacadores, la posibilidad de "equivocarse" y "salir" con un cliente que no les dé propina no dejará de estar presente; y en los supermercados ubicados en zonas con poblaciones de bajo nivel adquisitivo, muy a pesar de la experiencia acumulada por los empacadores, las posibilidades de recibir propina se verán disminuidas por las características socioeconómicas de la población. Este hecho se constata en las estadísticas de Verde (2002), en las que se registran mayores niveles de propina en barrios de estratos altos como Usaquén y Country, mientras que los promedios más bajos coinciden con locaciones de estratos medios-bajos como Restrepo, Suba y Ciudad Roma. Esta es, entonces, una tensión que deben enfrentar los empacadores: ¿cómo evadir la incertidumbre en un intercambio cuyo rasgo cultural distintivo es la incertidumbre misma? La respuesta quizá sea enfrentar siempre el azar y las variables socioeconómicas contextuales, “cogiendo ‘al vuelo' las oportunidades de provecho”, como diría Michel de Certeau.

EL DON, EL COOPERATIVISMO

Y LA SUBCONTRATACIÓN DE EMPACADORES DE SUPERMERCADOS

U ISTÓRICAMENTE, El ESQUEMA DE LAS COOPERATIVAS COMO VERDE ha estado asociado a una forma de concebir las relaciones laborales, en la cual se propende a la distribución equitativa del excedente producido; el beneficio colectivo de los asociados; y el manejo democrático de la entidad; entre otros factores. 


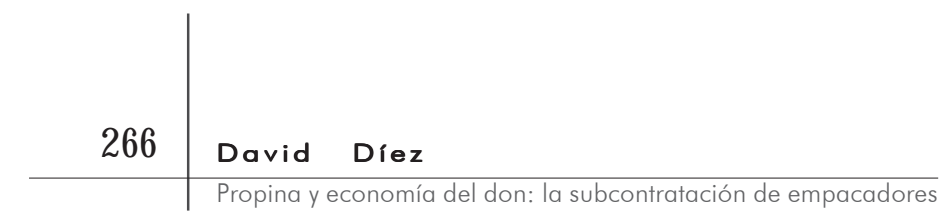

Sin embargo, en contraste con tal filosofía, Verde se ha conformado de modo tal que responde, más que a las necesidades de sus asociados, a una estrategia de Azul para reducir los costos de nómina de su personal de empaque. Así, la cooperativa funciona tal como lo haría una empresa temporal o en subcontratación (outsourcing).

Por subcontratación se puede entender la descentralización de los procesos productivos [o de servicios] en unidades de gestión y control de la fuerza de trabajo 'autónomas' y, por lo tanto, con una gestión administrativa en áreas geográficas separadas o discontinuas, de forma tal que la unidad empresarial dominante controla y articula las distintas unidades subordinadas, bajo la modalidad de contratos de productos semiacabados que ingresan o intervienen como insumos o servicios específicos para la producción de un determinado bien o servicio (...). De esta manera, los contratos laborales que los trabajadores sostenían con la propia empresa se sustituyen bajo el modo de contratos comerciales con prestadores de servicios (Bronstein, 1985: 87, citado por Urrea, 1999: 50).

El funcionamiento de cooperativas de trabajo asociado bajo el modelo de la subcontratación no constituye una excepción; al contrario, es un fenómeno que se está generalizando en Colombia y en otros países latinoamericanos como Chile, tanto en el sector privado como en el público (Jaramillo, 2004). Azul, como muchos otros supermercados de cadena del país, ha logrado un notable ahorro presupuestal al subcontratar a los empacadores. Antes de 1996, cuando la cadena de almacenes Éxito inauguró la Cooperativa de Trabajo Asociado Futuro bajo el visto bueno del entonces Ministerio de Trabajo y Seguridad Social (actual Ministerio de la Protección Social) y se comenzó a expandir su modelo, la mayoría de los empacadores eran empleados directos de los supermercados, recibían un salario mínimo junto con todas las prestaciones legales, y las propinas constituían un aliciente adicional por su trabajo. Desde 1996, debido a un uso acomodado de la legislación cooperativista colombiana, la propina ha sido resignificada y asumida como base fundamental del salario de los empacadores. Es decir, la propina pasó de ser un regalo a constituir "salario".

Según el testimonio del supervisor de personal de Verde, cuando esta cooperativa surgió, Azul señaló que el contrato que establecería con ella debía garantizarle una reducción cercana a 40\% en la nómina de su personal de empaque. Para el año 2002, 


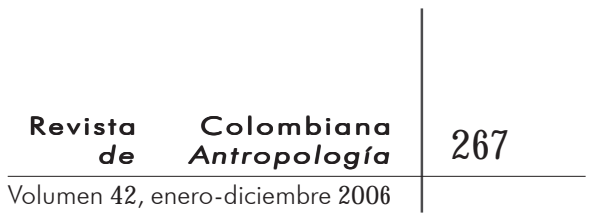

Azul cancelaba a Verde $\$ 1664$ por cada hora de trabajo de un empacador. Los empacadores suelen trabajar 156 horas al mes -de lunes a sábado, con un día de descanso entre semana, seis horas, y los domingos y festivos, nueve horas-. Así, salvo contadas excepciones, el trabajo mensual de un empacador representaba \$259.600 que Verde cobraba a Azul (Verde, 2002). Si consideramos que en 2002 el salario mínimo en Colombia era de $\$ 343000$-incluidos $\$ 34.000$ de subsidio de transporte-, vemos que Azul ahorraba $\$ 83400$ mensuales por cada uno de los 133 empacadores que en promedio estuvieron afiliados a Verde ese

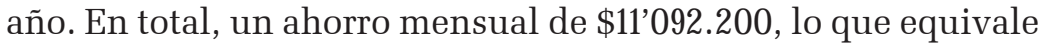
a $24 \%$ menos de lo que pagaba al contratar de manera directa a los empacadores. A lo anterior se debe sumar el ahorro representado en que Azul no paga la seguridad social de los empacadores, que constituye un porcentaje considerable del salario base; ni el costo de sus uniformes de trabajo; ni el de cesantías; ni el del personal ejecutivo encargado de administrar el servicio de empaque, entre otros factores. Todos estos rubros, excepto las cesantías, pues el estado no obliga a las cooperativas a pagarlas, los debía cubrir Verde mediante el uso de los \$259.600 recibidos por el trabajo mensual de cada empacador a su cargo.

Así mismo, Azul se ahorra el manejo de un sindicato, que no tiene cabida en el esquema cooperativista en el que se supone deben primar las relaciones horizontales. Este tipo de relaciones se ven minadas debido a factores que señalaré más adelante. De igual modo, Verde se evita lidiar con la insatisfacción y las quejas de los empacadores frente a la variación de los niveles de propinas recibidas durante sus jornadas de trabajo. Al igual que otras cooperativas, Verde sustenta con estadísticas que los empacadores reciben ingresos mensuales iguales o superiores al salario mínimo de acuerdo con jornadas de trabajo de seis horas diarias (Verde, 2002). Sin embargo, las medias estadísticas desdibujan las diferencias abismales entre los ingresos recibidos por empacadores de distintos supermercados ubicados en sectores con condiciones socioeconómicas diversas ${ }^{14}$. Estas diferencias tienden a agudizarse según la distancia o cercanía de las fechas de "quincena"15, el mes del año, entre otros aspectos de los ciclos comerciales urbanos.

14. Mientras los empacadores del supermercado de barrio Restrepo consideran que una "buena propina" corresponde a $\$ 500$, los del barrio Usaquén señalan que corresponde a $\$ 5000$ o $\$ 10.000$ (notas de campo).

15 Fechas del mes en las que muchos de los clientes de los supermercados, como la mayoría de asalariados, reciben el pago de sus sueldos y hacen mercado. 


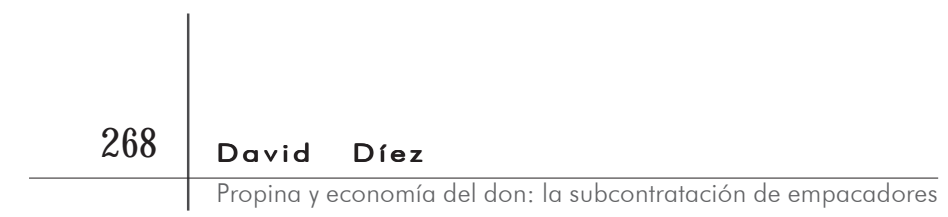

Así, vemos cómo el cooperativismo y la economía del don se conjugan en función de una de las tendencias estructurales del sistema económico capitalista, a la cual Marx (1946) hacía referencia hace ya más de un siglo: el aumento de la plusvalía relativa; es decir, la relación indirectamente proporcional entre la disminución de los salarios de la mano de obra y el aumento de la ganancia de los propietarios de los medios de producción. Tal tendencia lleva a que la contratación del obrero, o en este caso del empleado encargado de prestar un servicio en particular, cueste lo menos posible a la empresa que necesita de su fuerza de trabajo, generando así un aumento en los excedentes que recibe por la realización de su objetivo comercial, tratándose de Azul, por la venta de bienes de consumo al público en general.

El fenómeno descrito no constituye un caso aislado; al contrario, da cuenta de algunas características propias del capitalismo flexible contemporáneo o neocapitalismo, como lo denomina Richard Sennet (2000), entre otros autores. En este nuevo capitalismo, la mayoría de la mano de obra, tanto calificada como no calificada, se enfrenta a un mercado laboral "flexible" en el que imperan las empresas con estructuras dinámicas y con frecuentes e imprevisibles periodos de recortes de personal. El concepto de "flexibilidad" ha generado "nuevas estructuras de poder y control en lugar de crear condiciones de liberación" (Sennet, 2000: 48). Una de las expresiones de ese concepto en el mercado laboral es la generalización de empresas en outsourcing, que han tenido como objetivo permitir la re-ingeniería de instituciones productivas o de servicios, es decir, hacerlas más eficientes, llevar a que "hagan más con menos" (Sennet, 2000: 50). Verde es fruto de tal tipo de proceso. Su creación ha significado no sólo un ahorro presupuestal para Azul, sino también le ha garantizado a esta cadena de supermercados un servicio de mayor calidad. Antes de Verde no existía una serie de cargos medios que supervisaran de cerca la labor de los empacadores. La función que estos cumplen ahora era asumida por los auxiliares de mercadeo, quienes tenían un "jefe de cajas" que debía ejercer control no sólo sobre ellos, sino también sobre los cajeros y bodegueros, entre otros trabajadores. Ahora, en cambio, además del "jefe de cajas" existen los cargos de coordinador y supervisor de empacadores, mediante los que se garantiza un control mejor y más barato del servicio de empaque. 


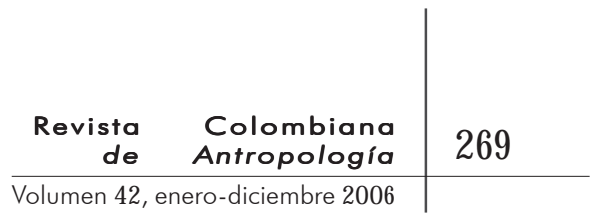

Otro de los elementos propios de las nuevas estructuras de control señaladas por Sennet es la concentración sin centralización del poder. Pese a que los planteamientos de quienes están a favor de la nueva organización flexible del trabajo señalan que esta "descentraliza el poder, es decir, que da a la gente de categoría inferior más control sobre sus propias actividades”, lo cierto es que la generalización de entidades en outsourcing, entre las que se dividen funciones que antes eran coordinadas y tenían lugar en una sola institución, permanecen bajo el dominio implícito de esa institución (Sennet, 2000). Mediante la creación de Verde, Azul ha concentrado su poder sin descentralizarlo. Esto lo comprobé mediante mi participación como vicepresidente del comité de administración de Verde entre febrero y agosto de 2003 En varias oportunidades noté que las decisiones gerenciales de la cooperativa se orientaban más en función de los intereses de altos ejecutivos de Azul que de las necesidades de sus asociados. Es por eso que señalé con anterioridad la inviabilidad de las relaciones horizontales en Verde. Para poner tan solo un ejemplo, uno de los proyectos que junto con otro asociado propusimos desarrollar como parte de nuestra gestión en el comité, fue establecer subsidios para los empacadores que trabajaran en las zonas en donde se registraran los menores niveles de propina. Para llevar a cabo este proyecto era necesario aumentar en cierto porcentaje el precio de la hora/empacador que Azul pagaba a Verde por su servicio en esas zonas. La propuesta fue aceptada cuando la presentamos ante el comité de administración de la cooperativa. Sin embargo, quince días después, la dirección ejecutiva de Verde nos comunicó que uno de los directivos departamentales de Azul la había llamado, notablemente ofuscado, para exigirle revocar nuestra propuesta o, de lo contrario, Azul no renovaría al año siguiente la orden de prestación de servicios mediante la cual contrata a Verde, y acudiría a cualquiera de las decenas de cooperativas dedicadas a prestar el servicio de empaque a supermercados de Bogotá y de otras ciudades del país.

Eventos como el anterior permiten decir que aun cuando en términos formales Verde es una institución autónoma, en la práctica, por medio de actos sutiles e informales -como llamadas telefónicas- se mantiene bajo el poder de decisión de Azul. Según Sennet, ese tipo de relación de poder caracteriza las "flexibles” empresas actuales. En teoría, se plantea que mediante el 


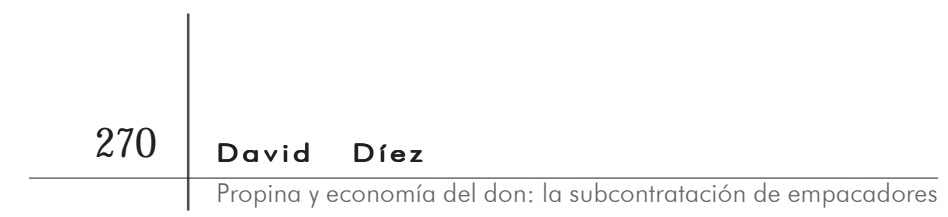

proceso de reingeniería institucional se generan entidades menos jerarquizadas. Sin embargo, lo que sucede es que "se complementa el poder para reorganizar una institución de arriba hacia abajo en fragmentos y nódulos de red". Se trata de una "libertad engañosa (...), la presión viene de la cumbre de la jerarquía institucional" (Sennet, 2000: 58).

Otra de las características del capitalismo flexible es la búsqueda constante de cambio por parte de las empresas. El riesgo y la incertidumbre son vistos como elementos con los cuales los trabajadores deben acostumbrarse a convivir, más que como factores negativos: siempre se empieza desde cero, nada que se haga hoy asegura algo a largo plazo (Sennet, 2000: 87). Y en un

16. En 2003, la tasa de desempleo de la población joven económicamente activa en Bogotá se ubicó en 29,34\% (CID, 2004: 53 a partir de datos del Dane).

desempleo en Bogotá y el mundo ${ }^{16}$, pasan a ser "protagonistas", por una supuesta capacidad de adaptarse a todo.

En un número reciente del California Managment Review, por ejemplo, se intentó explicar los puntos a favor de la juventud y los aspectos negativos de la edad en las organizaciones flexibles. Se argumentaba que los trabajadores mayores tienen modos de pensar inflexibles y son reacios al riesgo, y también carecen de la energía física necesaria para hacer frente a las exigencias de la vida en un trabajo flexible. (...) La flexibilidad es sinónimo de juventud; la rigidez es sinónimo de vejez (Sennet, 2000: 97).

Bajo la promoción de estos prejuicios sociales está la necesidad del sistema económico de contratar mano de obra barata. "En el capitalismo actual, [la] relación entre salario bajo y juventud aún existe" (Sennet, 2000: 97). En las cooperativas como Verde esta relación se camufla bajo el eslogan según el cual el trabajo que se brinda a jóvenes entre dieciocho y veinticuatro años constituye un "puente entre el mundo del estudio y del trabajo" (Almacenes ÉXITO, 2003). Aun cuando existen factores propios del trabajo de los empacadores, como la jornada laboral de seis horas, que les permiten contar con tiempo extra que se puede dedicar al estudio, este hecho no resta importancia al carácter precario de la compensación laboral constituida por propinas. Muchos jóvenes recién egresados de la educación 


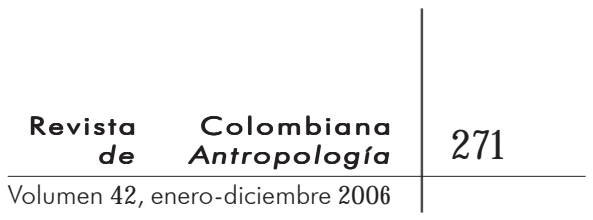

media, con pocas posibilidades de acceso a la educación superior y sin experiencia laboral, terminan aceptando trabajos como este en aras de insertarse en el sector productivo en un marco institucional. Estos jóvenes se enfrentan a diario al riesgo y a la incertidumbre. Llegan a sus puntos de trabajo y no saben cuánto costará su jornada laboral, es decir, cuántas propinas recibirán de los clientes. Pero en el nuevo capitalismo esta situación no constituye un problema, sino más bien un reto que debe ser asumido por los jóvenes.

El modelo de contratación en el cual los trabajadores reciben un "salario" constituido por las propinas de los clientes se ha implantado en Colombia siguiendo el ejemplo de los Estados Unidos de América. Allí, los resultados han sido positivos para los trabajadores y para los propietarios de supermercados, restaurantes y bares, entre otros establecimientos que han adoptado el modelo. Los propietarios han obtenido un ahorro presupuestal que les genera mayores ganancias, mientras que los trabajadores han conseguido un ingreso incluso mayor al salario mínimo mensual vigente en Estados Unidos. Lo anterior ha sido posible, entre otros factores, gracias a que en tal país existe un marco legal que, a diferencia del que rige a Colombia, es claro y estricto en cuanto a medidas de control sobre la propina, toda vez que establece proporciones específicas en las cuales esta debe ser dada, según los contextos comerciales en los que se inscriba. Así mismo, en algunos estados, por ejemplo, la propina se encuentra reglamentada por el Departamento de Trabajo, de manera que en espacios comerciales como los restaurantes en donde los meseros reciben un salario inferior al mínimo legal, el gerente debe compensar económicamente a sus trabajadores si estos no logran obtener propinas que permitan que su salario sea igual al mínimo establecido ${ }^{17}$. Pero más allá de la legislación, las condiciones socioeconómicas propias de la sociedad estadounidense

son radicalmente distintas a 17. Tomado de la página: htrp://www.tipping.org/ las de la sociedad colombia- TopPage.shtml (consultada el 26de abril de 2004). na. A diferencia de los consumidores de Estados Unidos, es poco probable que todos los clientes que hagan compras en los supermercados colombianos tengan suficiente capacidad adquisitiva como para dar propinas a los empacadores. Así, el implante de este modelo de contratación en el país muestra el afán de algunos sectores privilegiados 


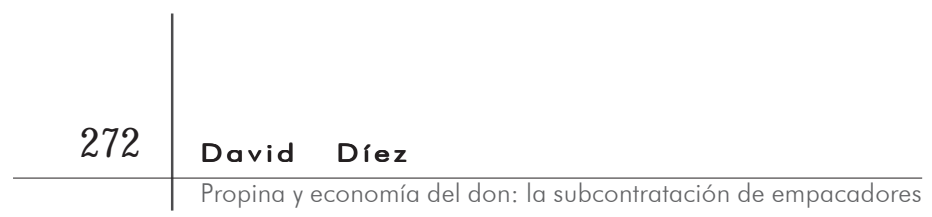

de la sociedad colombiana por imitar esquemas extranjeros, dando la espalda a las condiciones socioeconómicas del país.

La transformación de los vínculos salariales entre Azul y su personal de empaque forma parte de los cambios radicales en la historia de la relación salarial en las sociedades capitalistas; encaja en el retorno que se ha dado desde $\mathbf{1 9 7 0}$ hacia la desregulación y poca intervención estatal en las relaciones obrero-patronales propia del capitalismo salvaje del siglo diecinueve. Esta tendencia ha sido más aguda en Latinoamérica que en Norteamérica y Europa en general, e incluso hay quienes afirman que es la norma y no la excepción en la historia del capitalismo en los países latinoamericanos (Díaz, citado en Urrea, 1999). Para el caso colombiano puede decirse que la generalización del trabajo inestable es aún más marcada que en el resto de América latina, debido, entre otros factores, a que aquí no existió un movimiento populista que promoviera políticas redistributivas y legitimara en el imaginario político la equidad en la relación capital-trabajo asalariado y una mayor aceptación del sindicalismo en las instituciones sociales (Pécaut y Palacios, citados en Urrea, 2001).

\section{CONSIDERACIONES FINALES}

N LA ACTUALIDAD EXISTEN PROCESOS DE COMPRA Y VENTA DE MANO DE

- obra, como el descrito a propósito de los empacadores de su - permercados de Bogotá, en los que el uso del análisis propuesto en El Capital es especialmente importante. Así, aun cuando cada vez abundan más los estudios sobre la llamada sociedad de la información, en los que se ofrecen ricos análisis sobre la configuración de maneras nuevas y complejas de generación de capital por medio de procesos desligados de la producción y la venta de servicios, en Colombia hay grandes sectores, como el del mercadeo, cuyo funcionamiento presenta características clásicas de los tempranos procesos capitalistas. Es decir que no en todos los casos la información está sustituyendo los factores clásicos -mano de obra, energía, materiales, etcétera- en el ámbito de la producción mercantil y de servicios. Lo anterior señala la necesidad de retomar los importantes desarrollos de campos como la economía política clásica, y articularlos con los nuevos discursos de las ciencias sociales en general y la antropología en particular, con el fin de comprender 


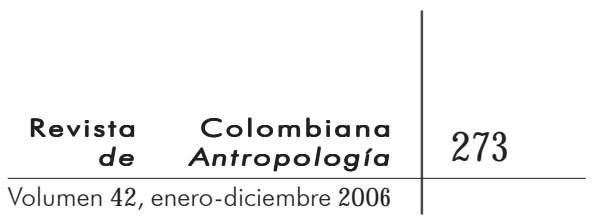

y, a la vez, tener una posición crítica frente a fenómenos económicos propios de las sociedades contemporáneas.

Por otro lado, es de resaltar también que la mayor parte de los estudios antropológicos relacionados con la economía del don han visto a esta como una resistencia de los sistemas económicos de sociedades "primitivas" frente al modelo económico capitalista imperante hoy en día (Ferraro, 2004). En contraste con esa mirada, el caso presentado muestra cómo los supermercados, al dejar en manos de los clientes la mayor parte de la compensación por el trabajo de los empacadores, han articulado el don a la lógica salarial propia del capitalismo, llevando a que el primero se presente, más que como resistencia, como una herramienta útil para generar ahorro presupuestal. Tras esta resignificación del don se encuentran tendencias estructurales propias del modelo capitalista, como el aumento de la plusvalía relativa (Marx, 1946).

El fenómeno estudiado muestra también que aun cuando en términos conceptuales se puedan categorizar diferentes formas de intercambio como el don, el cooperativismo y el neocapitalismo, en la práctica las fronteras de estas lógicas de transacción se difuminan, a tal punto que llegan a constituirse en una amalgama. Sin embargo, también es cierto que en medio de esa fusión predominan relaciones desiguales e inequitativas que caracterizan al capitalismo flexible actual.

Al mismo tiempo, es importante subrayar cómo los empacadores encuentran formas de adaptarse a las desigualdades propias de su panorama laboral, en las que cumple un papel importante la experiencia y puesta en escena de tácticas mediante las que hacen uso de la economía del don, constituyendo estereotipos en su interacción con los clientes de los supermercados y procurando así maximizar las oportunidades de recibir propina. Frente a las estrategias de adaptación de los empacadores, es importante indagar por el lugar que ocupa el trabajo en la configuración de sus trayectorias de vida, y en particular en la construcción de sus identidades de género (véase Díez, 2006). Es pertinente conocer las posibilidades y limitaciones que modelos de trabajo flexible como el expuesto, que tienden a generalizarse, brindan a las y los jóvenes para construir referentes subjetivos y estrategias de supervivencia y movilidad social, alrededor de modelos de pensar y ejercer la masculinidad/feminidad que apunten a la equidad social entre hombres y mujeres. 


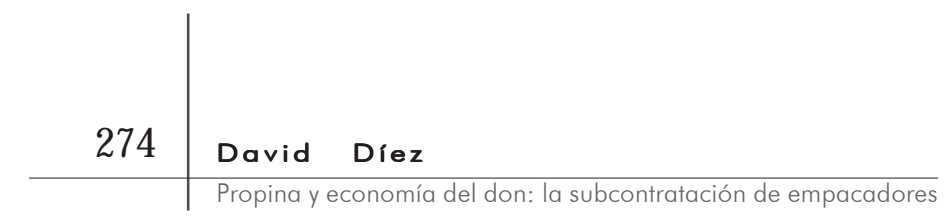

Por último, cabe enfatizar en la necesidad de que en Colombia se creen mecanismos efectivos de control estatal que eviten que grandes firmas comerciales utilicen el esquema cooperativista como fachada para obtener beneficios económicos pasando por encima de los derechos básicos de los trabajadores y minando los principios cooperativistas que, precisamente, buscan ser una opción productiva en la que las relaciones de poder y distribución de excedente sean más equitativas que las que caracterizan a las empresas capitalistas. Ya que el funcionamiento de las cooperativas de empacadores se ha dado bajo el modelo de la subcontratación, las cadenas de supermercados deberían contratar a empacadores que pertenezcan a entidades propias de ese modelo, como las empresas temporales. Así, los respectivos contratos estarían cobijados por el Código sustantivo del trabajo, no sería posible establecer la propina como compensación variable al trabajo de los empacadores, y estos recibirían no sólo el pago de su seguridad social, sino también el salario mínimo al que deben tener derecho todos los trabajadores en Colombia. Otra opción plausible sería expedir una reglamentación específica para las cooperativas de empacadores, que determine que estos deban recibir por su labor, al menos, un salario mínimo mensual vigente como remuneración.

\section{BiBLIOGRAFíA}

Almacenes ÉXito, 2003 "Las cooperativas y precooperativas de empacadores entregan balance de 2002". Informativo Publicitario. Bogotá.

Bourdieu, Pierre. 1997. Razones prácticas. Anagrama. Barcelona.

CAmargo, Alejandro. 2005 "La tierra del güayusé. Ecología, incertidumbre y escasez en el río San Jorge”. Trabajo de grado. Departamento de antropología. Universidad Nacional de Colombia. Bogotá.

Certeau, Michel De. 1996. La invención de lo cotidiano. Artes de hacer. Vol. 1 Universidad Iberoamericana. México.

CID. 2004. Situación socioeconómica de la juventud en Bogotá 20022003 DAAC. Bogotá.

DíEz, DAviD. 2006. “Trabajo de campo y '(anti)ceguera de género': apuntes para una investigación sobre carreras, pareja y mundo laboral de jóvenes en Bogotá". Cuadernos de la Escuela de Género. Universidad Nacional de Colombia. (En evaluación). 


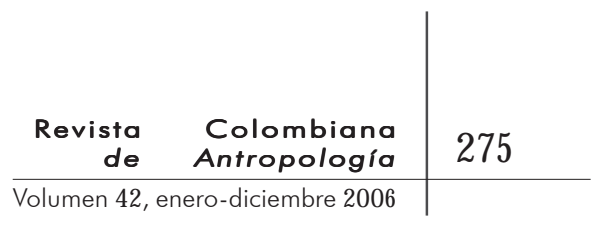

2005 "Entre 'cachetadas' y otros ardides: propina y lógicas de intercambio en supermercados de Bogotá". Trabajo de grado. Departamento de antropología. Universidad Nacional de Colombia. Bogotá.

Ferraro, Emilia. 2004. Reciprocidad, don y deuda. Flacso-Abya Yala. Quito.

Goffman, Erving. 1967. Ritual de la interacción. Tiempo Contemporáneo. Buenos Aires.

- 1959. La presentación de la persona en la vida cotidiana. Amorrortu Editores. Buenos Aires.

Jaramillo, Carlos. 2004. "Cooperativas de Trabajo Asociado". Revista Cultura y Trabajo. ๔. Escuela Nacional Sindical, ENS. Medellín.

Marx, Karl. 1946 [1867]. El Capital. Tomo I. Fondo de Cultura Económica. México.

Mauss, Marcel. 1971 [1925]. "Ensayo sobre el don”. En Sociología y antropología. Tecnos. Madrid.

Plattner, Stuart (ed.). 1989. Economic anthropology. Standford University Press. Standford.

República de Colombia. 2003 Código sustantivo del trabajo. Momo Ediciones. Bogotá.

1988. Ley 79. [Tomada de www.dansocial.gov.co, consultada en febrero de 2005.

Rosaldo, Renato. 1989. Cultura y verdad. Nueva propuesta de análisis social. Grijalbo. México.

Roseberry, WiLliam. 1997. "Marx and anthropology". Annual Review of Anthropology. 26.

Ruiz, Ximena, Mesa, María. 1985 "Criterios para reglamentar la propina”. Tesis de pregrado. Departamento de hotelería y turismo. Universidad Externado de Colombia. Bogotá.

SENNET, Richard. 2000. La corrosión del carácter: las consecuencias personales del trabajo en el nuevo capitalismo. Anagrama. Barcelona.

URRea, Fernando. 2001 "Globalización y prácticas de flexibilización laboral en grandes empresas: el caso colombiano". Ponencia presentada al Seminario internacional Complutense "El trabajo invisible: la desaparición social y científica del trabajo en la sociedad de la información”. Universidad Complutense. Madrid, 21y 22 de junio.

. 1999. "Globalización, subcontratación y desregulación laboral”. En Luz Gabriela Arango y Carmen Marina López (comp.). 
Globalización, apertura económica y relaciones industriales en América Latina. Universidad Nacional de Colombia. Bogotá.

VERDE. 2002. Informe anual. Documento de circulación limitada. Bogotá.

Recibido: 12 de agosto de 2005

Aprobado: 29de noviembre de 2005 